\title{
Home-Made Simple Experiment to Measure Sound Intensity using Smartphones
}

\author{
Ade Yeti Nuryantini ${ }^{*}$, Rizki Zakwandi ${ }^{2}$, Muhamad Ari Ariayuda ${ }^{3}$ \\ ${ }^{1}$ Physics Education Study Program, Faculty of Tarbiya and Teacher Training, UIN Sunan Gunung Djati Bandung, Indonesia \\ ${ }^{2}$ Magister Program of Physics Education, Faculty of Mathematics and Natural Sciences, Universitas Negeri Yogyakarta, Indonesia \\ ${ }^{3}$ Department of Mechanical Engineering, Universitas Diponegoro, Indonesia \\ *Corresponding Address: ade.yeti@ uinsgd.ac.id
}

\begin{tabular}{l}
\hline \hline Article Info \\
\hline Article history: \\
Received: January $27^{\text {th }}, 2021$ \\
Accepted: April $26^{\text {th }}, 2021$ \\
Published: May $5^{\text {th }}, 2021$ \\
\hline
\end{tabular}

\section{Keywords:}

Inverse square law, Sound meter,

Tone generator.

\begin{abstract}
The researchers present a simple experimental activity to measure the sound intensity level using an Android-based smartphone to prove the inverse square law and analyze the dependence of the sound intensity to the sound source frequency. The type of this study was quantitative research by conducting level of intensity experiment using a pair of smartphones with one smartphone functioning as the sound source using a tone generator free application (app) and the other smartphone functioning as the detector installed with Physics Toolbox sound meter application to measure the arriving sound intensity level. The smartphone functioning as the sound source was placed at a certain place labeled as the origin point $(0.0)$, while the other smartphone as the detector was placed at various distances on the $\mathrm{x}$-axis. In this study, the frequencies of the tone generator used were $500 \mathrm{~Hz}, 1000 \mathrm{~Hz}$, and $2000 \mathrm{~Hz}$. Then, the sound intensity level versus distance was analyzed to determine the compatibility between the experimental results using a smartphone and the prevailing theory, namely the inverse square model. The sound intensity level detected by the smartphone from $2,000 \mathrm{~Hz}$ resulted in the graph with smaller slope after passing 0.3 meters. The results follow the theorem of which the sound intensity level at the detector depends on the distance between the source and the detector based on the inverse square law. When the frequency of a source was changed $(500 \mathrm{~Hz}, 1000 \mathrm{~Hz}$ and 2000), the sound intensity also changed. Higher frequency leads to a larger sound intensity. The experiment can thus be used to assist high school students and physics undergraduates in understanding the inverse square law of sound or to study environmental noise with a simple and low-cost experiment.
\end{abstract}

\section{INTRODUCTION}

The COVID-19 pandemic since the beginning of 2020 has affected the educational process. Face-to-face learning activities in the school must be stopped and replaced with distance learning to prevent its spreading (Churiyah et al., 2020; Daniel, 2020). Various distance learning activities can be designed by teachers based on the students' condition in their respective schools and the characteristic of the lesson. Distance learning can be done electronically or through online learning by utilizing cellular technology and the Internet (Adnan \& Anwar, 2020; Ali, 2020; Puspitasari \& Oetoyo, 2018). Thus, distance learning could optimize the use of technology to support the learning process as learning media.

Teachers can utilize one of the technologies, namely smartphones. In physics learning, the smartphone has been commonly used as a learning tool to study physics concepts because it has many applications and sensors. One of the sensors 
in a smartphone is the sound meter. It is a measuring tool to assess the level of noise or sound intensity by measuring the sound pressure level. Sound level meters are also known as sound pressure level gauges (SPL), decibel gauges $(\mathrm{dB})$, noise gauges, or noise dosimeters. A sound level measuring device uses a microphone to pick up sound waves. The most common acoustic measurement unit for sound is decibels $(\mathrm{dB})$. However, some sound level measuring devices also use the equivalent continuous sound level (Leq) and other acoustic parameters (Dierecks et al., 2013)

Sound meter application in a smartphone has been widely used by previous researchers to explain the concepts of physics, including to determine the speed of sound propagation in air, liquid, and solids (Florea, 2019; Hellesund, 2019; Hirth et al., 2015; Kasper et al., 2015; Parolin \& Pezzi, 2015; Pereira da Silva et al., 2005; Staacks et al., 2019; Yafuz, 2015), to study the acoustic signals phenomenon (Ariz et al., 2017; Thees et al., 2017; Vogt et al., 2014), to analyze various types of sound waves (Kuhn \& Vogt, 2013), to analyze the oscillation phenomenon (Pili, 2020), to investigate the Doppler effect (Gómez-Tejedor et al., 2014; Osario et al., 2017; Wisman et al., 2018), and to analyze the interference (González et al., 2014; Hawley \& McClain, 2018; Yavuz \& Temiz, 2016).

The sound meter is quite potential to explain many physics phenomena, including the learning material about the inverse square law. The law states that the intensity is inversely proportional to the square of the distance. Unrestricted sound waves emitted from a source with power $(P)$ will be emitted uniformly in all directions. Assuming that the propagation medium does not absorb the power, the sound will spread uniformly with a constant total power $P$ over the area of a spherical radius $d$ (Apipah, 2016; Dias et al., 2016). The intensity of the sound, I, at a distance $\mathrm{d}$ is notated as (Fahy \& Thompson, 2016).

$$
I=\frac{P}{4 \pi d^{2}}=\frac{\text { const }}{d^{2}}
$$

This inverse square law is difficult for students to prove due to the unavailability of sound intensity level measuring devices in schools. The price of sound level meters is relatively expensive and less practical to be carried because of their large size (Hasan et al., 2016).

Other researchers have investigated the measurement of sound intensity and described the sound intensity profile using the Smart Chip WT5001 (Apipah, 2016) and using an Arduino-based Sound Level Meter (Apipah, 2016).

This study aims to determine the dependence of intensity level of the sound source versus distance to prove the inverse square law and to analyze the dependence on the sound intensity to the frequency of the sound source using a smartphone sensor. Smartphones can be used to measure sound intensity using sound level meter application. The sound level meter application is very easy to access and not expensive (Odenwald, 2020), hence students can easily conduct measurements of sound intensity and then use the results to analyze the relationship between the source-detector distance with the intensity.

The results are expected to provide an overview of the smartphones' sound meter application to develop a simple and straightforward experiment to assist high school students or physics undergraduates in understanding the inverse square law.

\section{METHODS}

The type of this study is quantitative research by conducting the level of intensity experiment using a smartphone. This study was conducted at the physics education laboratory of UIN Sunan Gunung Djati Bandung from June to September 2019 during the day at 10:00 - 12:00. The research design is displayed in Figure 1.

The research data were analyzed to see the compatibility between the experimental results using a smartphone and the theory, 
namely the inverse square model based on equations (1).

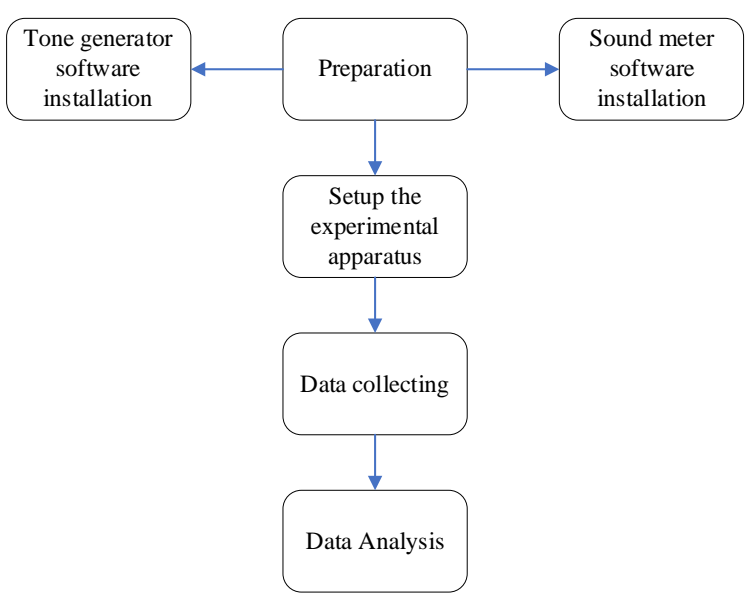

Figure 1. Research design

The experiment required two Androidbased smartphones, millimeter paper, pens, and rulers. The tone generator and sound meter applications were installed to the smartphones. The tone generator application served as the sound source while the sound meter application served as the detector to measure the sound intensity. In this study, the tone generator (Available online at https://play.google.com/store/apps/details?id =com.luxdelux.frequencygenerator)

application and the sound meter were found in the Physic Toolbox Sensor Suite downloaded from Google Play Store (Available online at https://www.vieyrasoftware.net/physicstoolbox-sensor-suite).

This research consisted of two experiments. The first experiment analyzed the inverse square law of sound level intensity. The second experiment analyzed the relationship of sound level intensity with frequency.

The smartphone as the sound source was placed on the point $(0,0)$ of millimeter block paper, while the smartphone with the sound meter sensor was placed at various points along the $\mathrm{x}$-axis. The tone generator with $2000 \mathrm{~Hz}$ was used for the first experiment and the sound level intensity at different locations was recorded $(0.02$ to $0.6 \mathrm{~m})$. Therefore, the value of sound intensity/relative sound level intensity as the function of distance can be established. In the second step, the frequencies of the tone generator used were $500 \mathrm{~Hz}, 1000 \mathrm{~Hz}$, and $2000 \mathrm{~Hz}$ with the distance of 0.02 to $0.3 \mathrm{~m}$ from the sound meter. In the experiment, the researchers took the averages of ten measurement values of the sound intensities. Then intensity level and distance data were analyzed to conclude a profile of the sound intensity $\mathrm{I}$ as a function of distance $\mathrm{x}$ using a graphic made by MS. Excel program. The results were then compared to inverse square law theory.

The sound meter application is very sensitive to sound, hence; noises can interfere with the aimed result. Therefore, the environment must be noise-free. In the experiment, noises affected the results. Therefore, the measured intensity of the sound meter was not fixed into one value and kept changing.

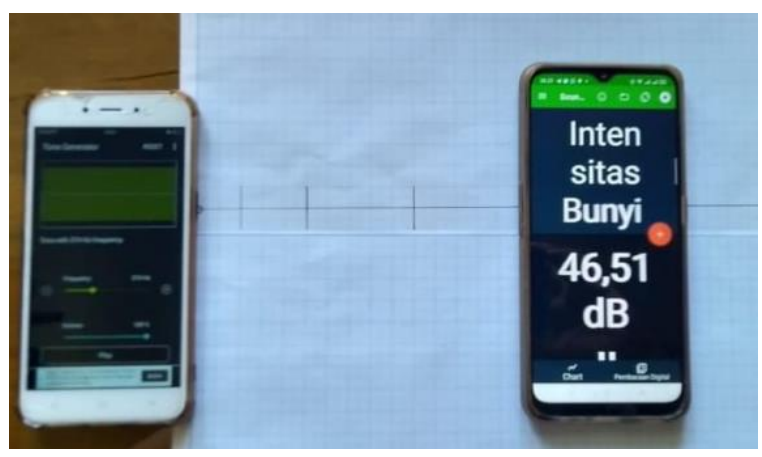

Figure 2. The Arrangement of the Experimental Apparatus

\section{RESULTS AND DISCUSSION}

The intensity and the sound intensity level are physics material learned by students in school on sound waves topic. To better understand this concept, high school students or physics undergraduates will get sound intensity data with distance variations from the measurement results of the sound meter on a smartphone.

The sound intensity level $(\beta)$ detected by the smartphone from $2,000 \mathrm{~Hz}$ was plotted as relative sound intensity level against distance as shown in Table 1 and Figure 3. 
Table 1. The Data of the sound intensity from the source with the frequency of $2000 \mathrm{~Hz}$ vs distance (from 0.02 to $0.6 \mathrm{~m}$ )

\begin{tabular}{cccccc}
\hline No & $\mathbf{d}(\mathbf{m})$ & $\mathbf{T I}(\mathbf{d B})$ & $\mathbf{N o}$ & $\mathbf{d}(\mathbf{m})$ & $\mathbf{T I}(\mathbf{d B})$ \\
\hline 1 & 0.02 & 96.30 & 16 & 0.19 & 79.53 \\
2 & 0.05 & 94.99 & 17 & 0.20 & 79.08 \\
3 & 0.06 & 92.49 & 18 & 0.21 & 78.30 \\
4 & 0.07 & 90.18 & 19 & 0.22 & 77.34 \\
5 & 0.08 & 88.99 & 20 & 0.23 & 77.80 \\
6 & 0.09 & 88.41 & 21 & 0.24 & 75.11 \\
7 & 0.10 & 86.93 & 22 & 0.25 & 76.06 \\
8 & 0.11 & 85.64 & 23 & 0.26 & 75.67 \\
9 & 0.12 & 85.04 & 24 & 0.27 & 72.13 \\
10 & 0.13 & 84.09 & 25 & 0.28 & 72.13 \\
11 & 0.14 & 83.90 & 26 & 0.29 & 71.58 \\
12 & 0.15 & 82.46 & 27 & 0.30 & 71.53 \\
13 & 0.16 & 80.98 & 28 & 0.40 & 70.71 \\
14 & 0.17 & 80.75 & 29 & 0.50 & 68.66 \\
15 & 0.18 & 80.13 & 30 & 0.60 & 66.74 \\
\hline
\end{tabular}

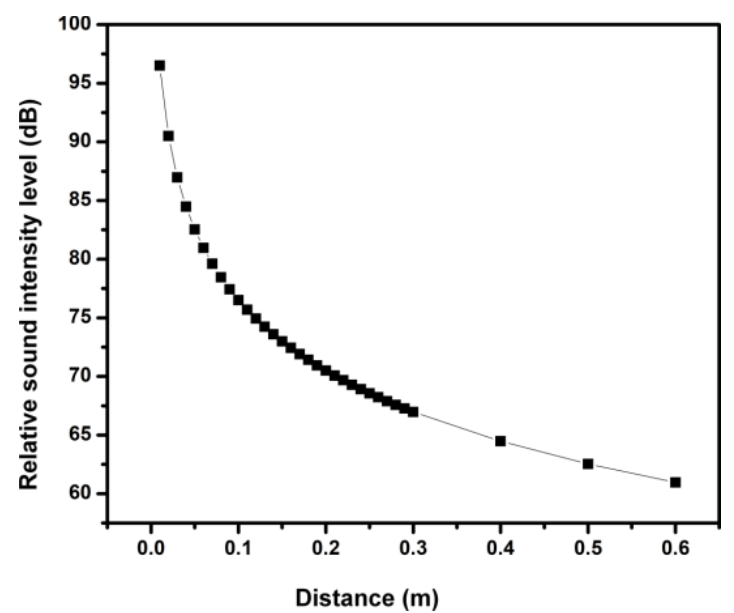

Figure 3. The graph of the sound intensity from the source with the frequency of $2000 \mathrm{~Hz}$ vs distance $(0.02-0.6 \mathrm{~m})$

Figure 3 shows the effect of distance on the intensity level measured by the sound level sensor of the smartphone. The sound intensity at the nearest distance $(0.02 \mathrm{~m})$ was found to be the highest $(96.3 \mathrm{~dB})$. As the sound source moved further away, the sound intensity captured by the sound meter decreased. At a distance of $0.6 \mathrm{~m}$, the intensity was $66.74 \mathrm{~dB}$. The intensity level decreases according to the inverse square law (Tsiatis, 2015). Another explanation said that the sound wave spread uniformly from a source with power $P$ (Watt) over a spherical form with a radius $d$, which can be assigned to the distance between the source and the detector (Meitei et al., 2020).

According to Figure 3, the slope of the graph tends to be smaller after passing a distance of $0.3 \mathrm{~m}$. This follows the theorem in equation 5 where the measured intensity level value decreases logarithmically as the distance between the sound source and the detector increases. Sound intensity is usually given on a logarithmic scale (Kumar, 2001). Equation 2-5 describes the results of the observations that show a logarithmic reduction in the intensity level (Trinh, 1994).

Soundwave is the propagation of energy emitted from a sound source spread to all directions so that the shape of the wavefront is spherical (Meitei et al., 2020). The energy of soundwave per unit time penetrating a unit area is called the sound intensity. If the sound source has a power of $P$ watts, the magnitude of the sound intensity at a distance $d$ from the sound source is:

$$
I=\frac{P}{A}=\frac{P}{4 \pi d^{2}}
$$

Where: $I=$ Sound intensity (watt $/ \mathrm{m} 2), P=$ Power of the source (watt or joule/s), $A=$ The surface area being penetrated by the soundwave $\left(\mathrm{m}^{2}\right), d=$ The distance from source to the detector $(\mathrm{m})$. From equation 1, the sound intensity decreases if the detector moves away from the sound source. In an indoor situation, the sound is reflected by the wall, so the decrease of the intensity by the increasing distance can be reduced.

If the source is placed in a room without obstructions, the sound spreads freely in all directions, so that the intensity of the content is inversely related to the square of the distance, or written in mathematical equation as $I \propto 1 / d^{2}$. If there are two detectors, A and $\mathrm{B}$, with a distance of $d_{1}$ and $d_{2}$ from the source, then the ratio of sound intensities of points A and B can be expressed as (de Mesnard, 2013),

$$
\frac{I_{A}}{I_{B}}=\frac{P / 4 \pi d_{A}^{2}}{P / 4 \pi d_{B}^{2}}=\frac{d_{B}^{2}}{d_{A}^{2}}
$$


The sound meter sensor on a smartphone measures the noise level in $\mathrm{dB}$ units, known as the sound intensity level $(\beta)$. The sound intensity level is a ratio between the intensity to the reference intensity $(I 0)$. The level of sound intensity is related to the hearing capability of human ear to sound waves ( $\mathrm{Li}$ \& Gong, 2016) that satisfies the logarithmic equation $R=k \log I$, where $R$ is the response to the sound intensity $I$, and $k$ is the proportionality constant. The sound intensity level is the logarithmic value of the ratio between the measured intensity to the hearing threshold $\left(I_{0}\right)$ written in the equation as:

$$
\begin{gathered}
\beta=10 \log \frac{I}{I_{0}} \\
\text { if } I_{0}=10^{-12} \mathrm{~W} / \mathrm{m}^{2} \text { then: } \\
\beta=-20 \log d+\left(10 \log \frac{P}{4 \pi}-120\right)
\end{gathered}
$$

Equation 5 represented by Figure 4 describes when the sound moves from the source, the sound intensity decreases inversely with the square of the distance.

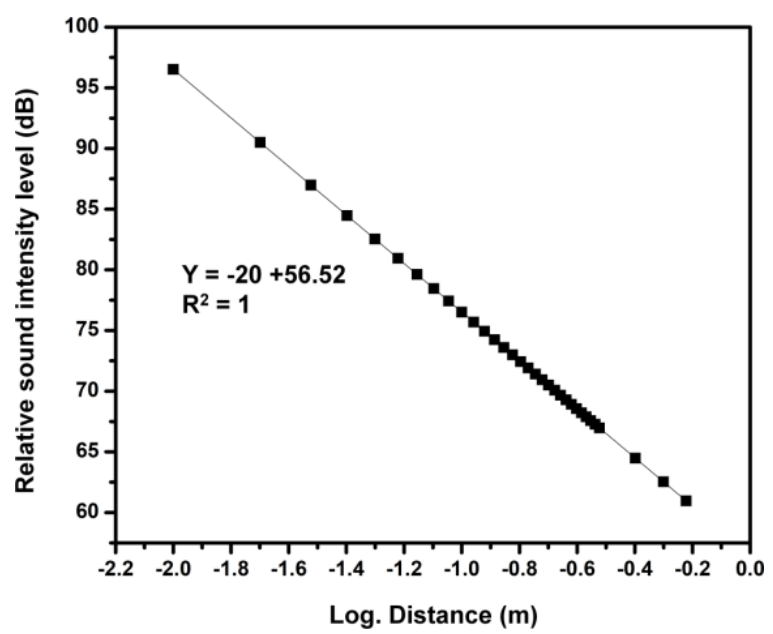

Figure 4. The graph of the sound intensity from the source with the frequency of $2000 \mathrm{~Hz}$ vs logarithm of distance $(0.02-0.6 \mathrm{~m})$

Figure 4 is the graphical representation of Equation 5 which shows the correlation between log.d and the measured intensity level in a linear form. According to the prevailing theory (Equation 5), the slope of the graph is -20 .
To find out the sound intensity and frequency relation, the sound intensity $(\beta)$ detected by the smartphone from three frequencies, $500 \mathrm{~Hz}, 1,000 \mathrm{~Hz}$, and 2,000 Hz is plotted against distance from $0.02 \mathrm{~m}$ to 0.3 $\mathrm{m}$. The results are presented in Figure 5 and Table 2.

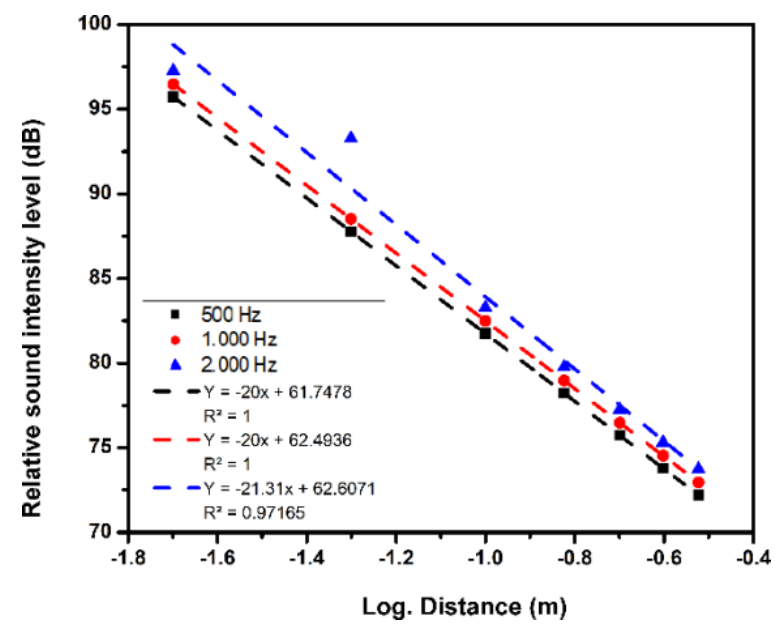

Figure 5. The graph of the sound intensity from the source with the frequency of $500 \mathrm{~Hz}, 1000$ $\mathrm{Hz}$ and $2000 \mathrm{~Hz}$ vs logarithm of distance (0.02-0.03 m)

Table 2. The difference in sound intensity level depends on the source.

\begin{tabular}{cccc}
\hline \multirow{2}{*}{ Distance $(\boldsymbol{m})$} & \multicolumn{3}{c}{ Sound intensity $\mathbf{( d B})$} \\
\hline 0.02 & 97.260 & $\mathbf{1 0 0 0} \mathbf{~ H z}$ & $\mathbf{5 0 0 ~} \mathbf{~ z z}$ \\
0.05 & 93.153 & 92.790 & 95.727 \\
0.10 & 87.047 & 86.083 & 77.727 \\
0.15 & 83.207 & 82.470 & 72.517 \\
0.20 & 79.082 & 78.773 & 68.930 \\
0.25 & 76.063 & 75.917 & 66.407 \\
0.30 & 71.533 & 70.010 & 62.630 \\
\hline
\end{tabular}

Figure 5 and Table 2 show the effect of different sources' frequencies on the results of measurements. Based on the slope of the graph, the frequency difference tends not to affect the slope significantly but has an impact on the reduction of the measured intensity level (see Table 2). The results are in line with the findings of other studies where there is a decrease in the sound intensity along with the decrease in frequency for the same distance (KuruvillaMathew et al., 2015). Also, for the same 
amplitude, the sound pressure is greater at higher frequencies (Olsson \& Linderholt, 2019). The intensity of the sound depends on the energy in the wave, which depends on the pressure. A pressure is a function of (displacement) amplitude and frequency. The intensity of the wave is proportional to the square of the amplitude and frequency of the wave given by the equation: $I=2 \pi^{2} \mu f A^{2} v^{2}$ where $\mu$ is density, $f$ is frequency, $A$ is the amplitude and $v$ is speed (Serway \& Jewett, 2018). From the equation, it is shown that higher frequency leads to larger sound intensity.

Sound is produced by a vibrating object that propagates through the medium (gas, liquid or solid) to produce sound waves. The sound which is moving away from the source spread in all directions. The inverse square law describes the relationship between sound intensity and distance. Measuring sound intensity using a sound meter on a smartphone proves that as the sound moves further away from the source, the sound level decreases. This experiment hopefully gives a new approach for physics laboratory or to study environmental noise with a simple and low-cost experiment.

\section{CONCLUSION AND SUGGESTION}

The level of sound intensity as a function of distance has been investigated and studied using sensors in the smartphones. The applications of the tone generator as the source of sound and the sound level meter to measure the sound intensity have been used in experiments. With the sensors and applications in the smartphone, it is easy for students to determine the level of sound intensity along with increasing distance. From the experimental results gathered, the data can be used by students to create a profile to describe the relationship of the sound intensity as a function of distance. From the graph, it can be shown that the sound intensity is inversely proportional to the square of the distance. The change of source frequency also changes the sound intensity. The increased of source frequency causes the sound intensity increased. The relationship between sound intensity with distance and sound intensity with frequency matches the theory. This study has offered a new procedure and methodology for the development of a simple and low-cost experiment to learn the concepts, measure, and analyze the sound intensity in physics learning.

\section{REFERENCES}

Adnan, M., \& Anwar, K. (2020). Online Learning amid the COVID-19 Pandemic: Students' Perspectives. Online Submission, 2(1), 45-51. https://doi.org/http://www.doi.org/10.3 3902/JPSP.\%202020261309

Ali, W. (2020). Online and remote learning in higher education institutes: A necessity in light of COVID-19 pandemic. Higher Education Studies, 10(3), 16-25. https://doi.org/https://doi.org/10.5539/h es.v10n3p16

Apipah, I. (2016). Distribution profile of sound level intensity with smart chip wt5001 using sound of blaganjur and cengceng. Journal Fisika, 5(6), 354362.

http://journal.student.uny.ac.id/ojs/ojs/i ndex.php/fisika/article/view/3402

Ariz, I. S., Giménez, M. H., Castro-Palacio, J. C., Gómez-Tejedor, J. A., \& Monsoriu, J. A. (2017). The smartphone as a sound level meter: Visualizing acoustical beats. Technica Industria, 318 , 34-38. http://www.tecnicaindustrial.es/TIFront al/sumario.aspx? $\mathrm{id}=108$

Churiyah, M., Sholikhan, S., Filianti, F., \& Sakdiyyah, D. A. (2020). Indonesia education readiness conducting distance learning in Covid-19 pandemic situation. International Journal of Multicultural and Multireligious Understanding, 7(6), 491-507.

Daniel, J. (2020). Education and the COVID19 pandemic. Prospects, 49(1), 91-96.

De Mesnard, L. (2013). Pollution models and 
inverse distance weighting: Some critical remarks. Computers and Geosciences, 52, 459-469. https://doi.org/10.1016/j.cageo.2012.11 .002

Dias, M. A., Carvalho, P. S., \& Ventura, D. R. (2016). How to study the doppler effect with audacity software. Physics Education, $\quad 51(3), \quad 35002$. https://doi.org/https://doi.org/10.1088/0 031-9120/51/3/035002

Dierecks, G. R., Ojha, S., Infusino, S., Maurer, R., \& Hartnick, C. J. (2013). Consistency of voice frequency and perturbation measures in children using cepstral analyses amovement toward increased recording stability. JAMA Otolaryngology-Head \& Neck Sur, 139(8), 811-816. https://doi.org/10.1001/jamaoto.2013.3 926

Fahy, F., \& Thompson, D. (2016). Fundamentals of sound and vibration. CRC Press.

Florea, C. (2019). Brief analysis of sounds using a smartphone. The Physics Teacher, 57(4), 214-215. https://doi.org/10.1119/1.5095371

Gómez-Tejedor, J. A., Castro-Palacio, J. C., \& Monsoriu, J. A. (2014). The acoustic doppler effect applied to the study of linear motions. European Journal of Physics, $35(2)$. https://doi.org/10.1088/01430807/35/2/025006

González, M. Á., Martín, M. E., \& Herguedas, M. (2014). Mobile phones for teaching physics: Using applications and sensors. Second International Conference on Technological Ecosystems for Enhancing Multiculturality - TEEM'14, 349-355.

Hasan, W. L., Wijayanto, I., \& Susatio, E. (2016). Design and implementation of audio meter based in android. EProceedings of Engineering, 3(3), 4371-4378

Hawley, S. H., \& McClain, R. E. (2018).
Visualizing sound directivity via smartphone sensors. The Physics Teacher, 56(2), 72-74. https://doi.org/10.1119/1.5021430

Hellesund, S. (2019). Measuring the speed of sound in air using a smartphone and a cardboard tube. Physics Education, 54(3). https://doi.org/10.1088/13616552/ab0e21

Hirth, M., Kuhn, J., \& Muller, A. (2015). Measurement of sound velocity made easy using harmonic resonant frequencies with everyday mobile technology. The Physics Teacher, 53(120). https://doi.org/10.1119/1.4905819

Kasper, L., Vogt, P., \& Strohmeyer, C. (2015). Stationary waves in tubes and the speed of sound. The Physics Teacher, 53(1), 52-53. https://doi.org/10.1119/1.4904249

Kuhn, J., \& Vogt, P. (2013). Analyzing acoustic phenomena with a smartphone microphone. The Physics Teacher, 51(118), 2-4. https://doi.org/10.1119/1.4775539

Kumar, N. (2001). A laboratory and field study of the attenuation of sound intensity using a whistle as the sonic generator. New Jersey Institute of Technology.

Kuruvilla-Mathew, A., Purdy, S. C., \& Welch, D. (2015). Cortical encoding of speech acoustics: Effects of noise and amplification. International Journal of Audiology, 54(11), 852-864. https://doi.org/http://doi.org/https://doi. org/10.3109/14992027.2015.1055838

Li, L., \& Gong, Q. (2016). The early component of middle latency auditoryevoked potentials in the process of deviance detection. NeuroReport, 27(10), 769-773. https://doi.org/http://doi.org/10.1097/W NR.0000000000000611

Meitei, S. N., Borah, K., \& Chatterjee, S. (2020). Modelling of acoustic wave propagation due to partial discharge and its detection and localization in an oil- 
filled distribution transformer. Frequenz, 74(1-2), 73-81. https://doi.org/https://doi.org/10.1515/f req-2019-0050

Odenwald, S. (2020). Smartphone sensors for citizen science applications: Light and sound. Citizen Science: Theory and Practice, $5(1)$. https://doi.org/http://doi.org/10.5334/cs tp. 254

Olsson, J., \& Linderholt, A. (2019). Force to sound pressure frequency response measurements using a modified tapping machine on timber floor structures. Engineering Structures, 196, 109343. https://doi.org/10.1016/j.engstruct.2019 .109343

Osario, M., Pereyra, C. J., Gau, D. L., \& Laguarda, A. (2017). Measuring and characterizing beat phenomena with a smartphone. European Journal of Physics, 39(2), 1-12. https://doi.org/10.1088/13616404/aa9034 Manuscript

Parolin, S. O., \& Pezzi, G. (2015). Kundt's tube experiment using smartphones. Physics Education, 50(4), 443-447. https://doi.org/10.1088/00319120/50/4/443

Pereira da Silva, W., Precker, J. W., e Silva, D. D. P. S., \& e Silva, C. D. P. S. (2005). The speed of sound in air: An at-home experiment. The Physics Teacher, 43(4), 219-221. https://doi.org/10.1119/1.1888080

Pili, U. B. (2020). Sound-based measurement of $g$ using a door alarm and a smartphone: Listening to the simple pendulum. Physics Education, 55(3). https://doi.org/10.1088/13616552/ab6e00

Puspitasari, K. A., \& Oetoyo, B. (2018). Successful students in an open and distance learning system. Turkish Online Journal of Distance Education, 19(2), 189-200. https://doi.org/https://doi.org/10.17718/ tojde. 415837

Serway, R. A., \& Jewett, J. W. (2018). Physics for scientists and engineers. Cengage learning.

Staacks, S., Heinke, H., \& Stampfer, C. (2019). Simple time-of-flight measurement of the speed of sound using smartphones. The Physics Teacher, 57(112). https://doi.org/10.1119/1.5088474

Thees, M., Hochberg, K., Kuhn, J., \& Aeschlimann, M. (2017). Adaptation of acoustic model experiments of STM via smartphones and tablets. The Physics Teacher, 55(7), 436-437. https://doi.org/10.1119/1.5003749

Tipler, P. A., \& Mosca, G. P. (2010). Physics for scientists and engineers: With modern physics. Wh Freeman.

Trinh, V. (1994). Measurement of sound intensity and sound power. In DSTOMaterials Research Laboratory.

Tsiatis, N. E. (2015). Understanding distance shooting and the type of rearm from the analysis of gunshot sounds. European Police Science and Research Bulletin, 15, 93-107.

Vogt, P., Hirth, M., \& Kuhn, J. (2014). Analyzing the acoustic beat with mobile devices. The Physics Teacher, 52, 248250. https://doi.org/10.1119/1.4868948

Wisman, R. F., Spahn, G., \& Forinash, K. (2018). Time measurements with a mobile device using sound. Physics Education, 52, 035012.

Yafuz, A. (2015). Measuring the speed of sound in water. Physics Education, 50(6), 727-732. https://doi.org/10.1088/00319120/50/6/727

Yavuz, A., \& Temiz, B. K. (2016). Detecting interferences with iOS applications to measure speed of sound. Physics Education, 51(1). $\quad$ https://doi.org/10.1088/00319120/51/1/015009 